\title{
An audit of positive findings in flexible and rigid check cystoscopy
}

\author{
Capt SR Keoghane \\ MS,FRCS,RAMC(V) \\ Urology Specialist Registrar
}

\author{
Mr AWS Ritchie \\ MD,FRCS(Ed)
}

Consultant Urological Surgeon

\author{
Wg Cdr (Retd) DJ Jones \\ FRCS \\ Consultant Urological Surgeon
}

Dept of Urology, Gloucestershire Royal Hospital, Great Western Road, Gloucester

SUMMARY: Both flexible and rigid cysto-urethroscopy are routinely used in the surveillance of transitional cell bladder tumours. This study addressed the issue of patient selection for either rigid or flexible cystoscopy. What proportion of positive findings at flexible cystoscopy and negative findings at rigid cystoscopy are acceptable? Standards were set of $10 \%$ for the former and $50 \%$ for the latter and our practice was then audited. A retrospective analysis of 800 patients undergoing check cystoscopy revealed a positive finding rate of $8.3 \%$ using the flexible instrument and $48.1 \%$ using the rigid instrument.

\section{Introduction}

Tsuchida and Sugawara (1) first used a flexible endoscope to examine the bladder in 1973, and some nine years later Burchardt (2) described his experience with over 100 cystourethroscopies.

Webb et al (3) described a small series of 23 patients who all underwent both flexible and rigid cystoscopy. In two male patients, multiple small papillary tumours were missed on flexible cystoscopy.

Clayman et al (4) performed both rigid and flexible cystoscopy in 80 patients under topical anaesthesia with or without intravenous sedation reporting no difference between rigid and flexible cystoscopy in the number of bladder tumours missed. Walker et al (5) in the setting of a blind study, carried out both flexible and thorough rigid cystoscopy in 53 patients and found that $9 \%$ of tumours were missed by either method. More recently, Wedderburn et al (6) have advocated treatment of recurrent papillary tumours using flexible cystodiathermy. A total of 171 flexible cystodiathermies were performed on 103 patients, only one needing to be abandoned due to pain. However no information was given as to how many patients required a rigid procedure after the initial flexible examination.

Overall, we were unable to identify 'ideal' positive finding rates using either flexible or rigid endoscopes from a review of the literature.

\section{Methods}

A combined meeting of Gloucestershire urologists set the standards prior to this retrospective audit. A positive finding rate of $10 \%$ during check flexible cystoscopy and $50 \%$ during check rigid cystoscopy was considered acceptable practice. The time period studied was 1 Oct 95 until 30 Sep 96. Flexible cystoscopy was carried out in a dedicated consultant led day surgery unit using an Olympus CYF-2 flexible cystoscope. Rigid check cystoscopy was carried out as both an inpatient and day case procedure under general anaesthetic. Clinical data were recorded and analysed using AuditBase ${ }^{\mathrm{TM}}$, a Windows relational database designed for medical patient care $(7,8,9)$. The British Association of Urological Surgeons recommended variations of OPCS4 coding were used to record and identify different types of cystoscopy.
Table 1

Breakdown of procedures by ASA grade

\begin{tabular}{|llcc|}
\hline & ASA1 & ASA2 & ASA3 \\
\hline Rigid & $\mathrm{n}=109(27 \%)$ & $\mathrm{n}=234(58 \%)$ & $\mathrm{n}=60(15 \%)$ \\
Flexible & $\mathrm{n}=160(40 \%)$ & $\mathrm{n}=188(47 \%)$ & $\mathrm{n}=51(13 \%)$ \\
\hline
\end{tabular}

Table 2

Breakdown of procedure by grade of surgeon

\begin{tabular}{|llll|}
\hline & Consultant & Registrar & $\begin{array}{c}\text { Senior House } \\
\text { Officer }\end{array}$ \\
\hline Rigid & $\mathrm{n}=181(45 \%)$ & $\mathrm{n}=169(42 \%)$ & $\mathrm{n}=53(13 \%)$ \\
Flexible & $\mathrm{n}=227(57 \%)$ & $\mathrm{n}=100(25 \%)$ & $\mathrm{n}=72(18 \%)$ \\
\hline
\end{tabular}

There was no departmental policy as to which procedure was required following diagnosis of transitional cell cancer, although those patients with a 'favourable tumour' that is superficial and of low grade would tend towards flexible examination after a negative first rigid check. Co-morbidity was also taken into account when making this decision.

\section{Results}

Operative details on a total of 399 flexible cystoscopies and 403 rigid cystoscopies that were carried out during the study period were retrieved from AuditBase. The breakdown of procedure by ASA (American Society of Anaesthesiology) grade and status of surgeon is shown in Tables 1 and 2 .

A positive finding rate of $8.3 \%$ using the flexible instrument and $48.1 \%$ using the rigid instrument was revealed.

\section{Discussion}

The choice of flexible or rigid cystoscopy and the intervals between examinations in the follow up of bladder tumours is subject to enormous variation. The obvious goal would be a $100 \%$ correlation between rigid and flexible cystoscopies. However, some urologists would argue for routine flexible cystoscopy in every case - there must obviously be a trade-off between logistical burden and the risk of morbidity from 
anaesthesia.

Rigid cystoscopy may be necessary where multiple biopsies are required for example following previous diagnosis of a potentially aggressive tumour, and a general or regional anaesthetic does facilitate staging with full pelvic examination, and biopsy of the base of a previously resected unfavourable tumour.

In this audit, the difference in grade of surgeon between rigid and flexible cystoscopy illustrates the fact that the majority of the flexible cystoscopies were performed in a consultant led, dedicated day case surgery unit. The number of rigid examinations was more equally split between consultant and junior staff reflecting a higher number of in-patient examinations.

The standards set in this retrospective audit were deemed not unreasonable although it must be emphasised that they were personal opinions of 'good practice'.

\section{REFERENCES}

1. Tsuchida SD, Sugawara H. A new flexible fibercystoscope for visualisation of the bladder neck. J Urol 1973; 109: 830.

2. Burchardt P. The flexible panendoscopy. J Urol 1982; 127: 479 .
3. Webb DR, Butler MR, FitzPatrick JM. Flexible cystourethroscopy : Advantages and limitations. Eur Urol 1984; 10: 336-337.

4. Clayman R, Pratap R, Lange PH. Flexible fiberoptic and rigid-rod lens endoscopy of the lower urinary tract : A prospective controlled comparison. J Urol 1984; 131: 715716.

5. Walker L, Liston TG, Lloyd-Davies RW. Does flexible cystoscopy miss more tumours than rod lens examination. Br J Urol 1993; 72: 449-450.

6. Wederburn AW, Ratan P, Birch BR. Outcome after treatment of recurrent transitional cell carcinoma of the bladder by flexible cystodiathermy. Br J Urol 1997; Suppl 4: 29.

7. Gilbert HW, Hartley RH, Simpson AD, Jones DJ, RITCHIE AWS. Fax that discharge! Hospital Update 1994; 20: 217.

8. Jones G. Lose Patience with lost patients. HealthCare Management 1993; November, 23-24.

9. Braithwaite BD, Ritchie AWS, Earnshaw JJ. Natali - A model for national computer databases in the investigation of new therapeutic techniques. J R Soc Med 1995; 88: 511515. 